\title{
NASATM-2003-211185
}

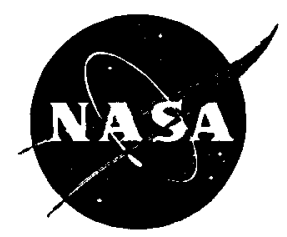

\section{On the Propagation of Plane Acoustic Waves in a Duct With Flexible and Impedance Walls}

\section{Abdelkader Frendi}

University of Alabama in Huntsville

Huntsville, Alabama

\section{Bruce Vu}

NASA YA-C2-T

John F. Kennedy Space Center, Florida 
Since its founding, NASA has been dedicated to the advancement of aeronautics and space science. The NASA Scientific and Technical Information (STI) Program Office plays a key part in helping NASA maintain this important role.

The NASA STI Program Office is operated by Langley Research Center, the Lead Center for NASA's scientific and technical information. The NASA STI Program Office provides access to the NASA STI Database, the largest collection of aeronautical and space science STI in the world. The Program Office is also NASA's institutional mechanism for disseminating the results of its research and development activities. These results are published by NASA in the NASA STI Report Series, which includes the following report types:

- TECHNICAL PUBLICATION. Reports of completed research or a major significant phase of research that present the results of NASA programs and include extensive data or theoretical analysis. Includes compilations of significant scientific and technical data and information deemed to be of continuing reference value. NASA's counterpart of peer-reviewed formal professional papers but has less stringent limitations on manuscript length and extent of graphic presentations.

- TECHNICAL MEMORANDUM. Scientific and technical findings that are preliminary or of specialized interest, e.g., quick release reports, working papers, and bibliographies that contain minimal annotation.

Does not contain extensive analysis.

- CONTRACTOR REPORT. Scientific and technical findings by NASA-sponsored contractors and grantees.
- CONFERENCE PUBLICATION. Collected papers from scientific and technical conferences, symposia, seminars, or other meetings sponsored or cosponsored by NASA.

- SPECIAL PUBLICATION. Scientific, technical, or historical information from NASA programs, projects, and missions, often concerned with subjects having substantial public interest.

- TECHNICAL TRANSLATION. Englishlanguage translations of foreign scientific and technical material pertinent to NASA's mission.

Specialized services that complement the STI Program Office's diverse offerings include creating custom thesauri, building customized data bases, organizing and publishing research results ... even providing videos.

For more information about the NASA STI Program Office, see the following:

- Access the NASA STI Program Home Page at http:www.sti.nasa.gov

- E-Mail your question via the Internet to help@sti.nasa.gov

- Fax your question to the NASA STI Help Desk at (301) 621-0134

- Telephone the NASA STI Help Desk at (301) 621-0390

- Write to:

NASA STI Help Desk NASA Center for AeroSpace Information 7121 Standard Drive Hanover, MD 21076-1320 


\title{
NASATM-2003-211185
}

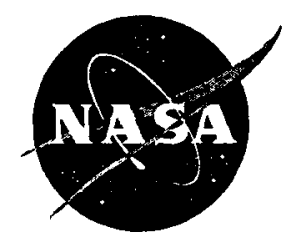

\section{On the Propagation of Plane Acoustic Waves in a Duct With Flexible and Impedance Walls}

\author{
Abdelkader Frendi \\ University of Alabama in Huntsville \\ Huntsville, Alabama \\ Bruce Vu \\ NASA YA-C2-T \\ John F. Kennedy Space Center, Florida
}

National Aeronautics and Space Administration

John F. Kennedy Space Center, Kennedy Space Center, Florida 32899-0001 


\begin{abstract}
This Technical Memorandum (TM) discusses the harmonic and random plane acoustic waves propagating from inside a duct to its surroundings. Various duct surfaces are considered, such as rigid, flexible, and impedance. In addition, the effects of a mean flow are studied when the duct alone is considered. Results show a significant reduction in overall sound pressure levels downstream of the impedance wall for both mean flow and no mean flow cases and for a narrow duct. When a wider duct is used, the overall sound pressure level (OSPL) reduction downstream of the impedance wall is much smaller. In the far field, the directivity is such that the overall sound pressure level is reduced by about 5 decibels $(\mathrm{dB})$ on the side of the impedance wall. When a flexible surface is used, the far field directivity becomes asymmetric with an increase in the OSPL on the side of the flexible surface of about $7 \mathrm{~dB}$.
\end{abstract}

\title{
ACKNOWLEDGEMENT
}

The authors would like to thank Dr. Max Kandula for initial discussions regarding problem formulations and to acknowledge Mr. Greg Moster at Wright-Patterson Air Force Research Laboratory (AFRL) for his continual support. Thanks are also due to all NASA KSC management for their encouragement of research and development efforts integral to the Launch Systems Testbed (LST). This project is funded by AFRL under grant MIPR-NGWRVA00272323. 


\section{TABLE OF CONTENTS}

$\underline{\text { Section }}$

Title

$\underline{\text { Page }}$

1.

INTRODUCTION.

\section{LIST OF FIGURES}

(a) Pressure distribution in the duct for $\Omega=2$, (b) Time history of the pressure fluctuations at $\mathrm{x}=\lambda$

(a) Pressure distribution in the duct for $\Omega=8$, (b) Time history of the pressure fluctuations at $\mathrm{x}=\lambda$

(a) Pressure distribution in the duct for $\Omega=2 \pi$, (b) Time history of the pressure fluctuations at $\mathrm{x}=\lambda$

Instantaneous pressure contours in the duct for $\mathrm{M}_{\mathrm{pk}}=\mathbf{0}$

Overall Sound Pressure Level (OSPL) along the top wall of the duct.

Sound Pressure Level along the top wall for the various frequencies and for the case of the impedance bottom with $M_{p k}=0$

Sound Pressure Level along the top wall for $f=1000 \mathrm{~Hz}$ and for the case of the impedance bottom with $M_{p k}=0$ 


\section{LIST OF FIGURES (cont)}

Comparison of pressure power spectra at the center of the top wall of the duct obtained with the various surfaces.

10 Comparison of the time history of the fluctuating pressure at the center of the top wall of the duct obtained for the various surfaces

11 Comparison of the instantaneous spatial variation of the fluctuating pressure obtained for the various surfaces

Instantaneous pressure contours in the duct for $\mathrm{M}_{\mathrm{pk}}=\mathbf{0 . 5}$

Overall Sound Pressure Level along the top wall of the duct

Comparison of pressure power spectra at the center of the top wall

Comparison of the instantaneous spatial variation of the fluctuating pressure obtained for the various surfaces

rigid and impedance surface cases $\left(M_{p k}=0, f=500 \mathrm{~Hz}\right)$

Instantaneous pressure contours in the duct and its surroundings for the rigid and the impedance-flexible surface cases $\left(M_{p k}=0, f=500 \mathrm{~Hz}\right)$

Far field SPL directivity obtained with the various surfaces at a distance of 2 feet from the exit of the duct $\left(M_{p k}=0\right)$

Comparison of the time history of the fluctuating pressure 2 feet downstream from the exit of the duct $\left(M_{\mathrm{pk}}=0\right)$. 


\section{INTRODUCTION}

Low noise emission has become the main focus of all modern machinery. For launch vehicles, the problem is even more severe as the vibroacoustic environment is very harsh on all surrounding structures. Current launch platform technology is very cumbersome and expensive to maintain; therefore, there is an urgent need for simpler and less expensive platforms with faster turnaround. In order to achieve this goal, a better understanding of the vibroacoustic environment during launch is needed. To this end, the Launch System Testbed at NASA Kennedy Space Center has designed a series of experiments ${ }^{1}$ to test new launch pad technologies.

One of the ideas being considered is to direct the exhaust plume into ducts in order to shield the launch vehicle from the initial blast wave and the harsh vibroacoustic environment. This will eliminate the expensive and cumbersome water injection technology currently in use. In this TM, an attempt is made at understanding the propagation of plane acoustic waves over various duct surfaces in the presence and absence of a mean flow. Numerical solution of acoustic problems requires a high order of accuracy of the numerical technique being used. In this study, the modified MacCormack scheme (Gottlieb and Turkel ${ }^{2}$ ) is used. The scheme is second-order accurate in time and fourth-order accurate in space. This level of accuracy is known to be sufficient for the resolution of acoustic problems ${ }^{3}$. In order to resolve sharp gradients without spurious oscillations, the fourth-order dissipation of Jameson et al. ${ }^{4}$ is used.

In addition to the accuracy of the scheme, the correct and nonreflective implementation of the boundary conditions is critical. In this case, all boundary conditions are derived using the method of characteristics ${ }^{5,6,7}$ and the far field radiation boundary condition of Bayliss and Turkel. ${ }^{8}$ Ozyoruk and Long ${ }^{9}$ showed that a frequency-dependent impedance boundary condition could be used in the time domain. Their results were in excellent agreement with impedance tube measurements ${ }^{10}$. In this TM, a more generic nonfrequency-dependent impedance boundary condition is used. When a flexible surface is used, a fully coupled approach is used to couple the vibration of the surface to the surrounding fluid ${ }^{11,12,13}$. Full coupling is very important in this case, as the pressure loading on the surface is very high.

\section{ACOUSTIC MODELS}

\subsection{FORMULATION}

The problem being addressed is that of plane acoustic waves propagating in a duct with various wall boundary conditions; i.e., rigid, impedance, and flexible walls. Two computational domains are used - one representing the duct alone and the other the duct and its surrounding medium. In the case of the duct alone, the mean flow effects are included as in ${ }^{9}$. The governing equations for the fluid medium are given by the nonlinear Euler equations written as

$$
\frac{\partial Q}{\partial t}+\frac{\partial F}{\partial x}+\frac{\partial G}{\partial y}=0
$$

where $Q$ is the vector $(\rho, \rho u, \rho v, e)^{T}$ with $\rho$ being the density, $\rho u$ and $\rho v$ the $x$ and $y$ 
momentum fluxes, respectively; and $e$ the total energy per unit volume given by

$$
e=0.5 \rho\left(u^{2}+v^{2}\right)+\rho c_{v} T .
$$

In Eq. (1), the functions $F$ and $G$ are;

$$
F=\left(\begin{array}{c}
\rho u \\
\rho u^{2}+p \\
\rho u v \\
u(e+p)
\end{array}\right), \quad G=\left(\begin{array}{c}
\rho v \\
\rho u v \\
\rho v^{2}+p \\
v(e+p)
\end{array}\right)
$$

In addition to Eq. (1), an ideal gas state equation is used

$$
p=\rho R T
$$

where $p$ is the pressure, $R$ the gas constant, and $T$ the temperature.

When a flexible surface is used on one of the duct walls, the motion of the surface is governed by

$$
D \frac{\partial^{4} \eta}{\partial x^{4}}-\bar{N}_{x} \frac{\partial^{2} \eta}{\partial x^{2}}+\rho_{p} h \frac{\partial^{2} \eta}{\partial t^{2}}+\Gamma \frac{\partial \eta}{\partial t}=\Delta p
$$

where $\eta$ is the plate transverse displacement, $\rho_{p}$ the plate material density, $h$ the plate thickness, and $\Gamma$ the structural damping. In Eq. (5), $D=E h^{2} / 12\left(1-v^{2}\right)$ is the plate stiffness with $E$ being the modulus of elasticity and $v$ the Poisson ratio of the plate material. The coefficient $\bar{N}_{x}$ in Eq. (5) is given by

$$
\bar{N}_{x}=\frac{E h}{2 L} \int_{x_{0}}^{x_{0}+L}\left(\frac{\partial \eta}{\partial x}\right)^{2} d x
$$

which represents the tension created by stretching of the plate due to bending. In Eq. (6) $x_{0}$ is the origin of the flexible plate and $L$ its length. The forcing term on the right-hand side of Eq. (5) is

$$
\Delta p=p^{\text {duct }}-p^{\text {outside }}
$$

where $p^{\text {duct }}$ is the pressure along the interior wall of the duct and $p^{\text {ouside }}$ is that from the ambient surrounding fluid, respectively.

Equations (1)-(7) are written in a nondimensional form using the following reference quantities for the different variables; 


$$
\begin{aligned}
& (x, y, \eta)_{r e f}=l_{r e f}, \quad t_{r e f}=\frac{l_{r e f}}{c_{\infty}} \quad \text { and } \quad T_{\text {ref }}=\frac{c_{\infty}^{2}}{c_{v}} \\
& \rho_{r e f}=\rho_{\infty}, \quad\left(u, v, \frac{\partial \eta}{\partial t}\right)_{r e f}=c_{\infty} \text { and }(p, e)_{r e f}=\rho_{\infty} c_{\infty}^{2}
\end{aligned}
$$

The free stream properties used are those of air at ambient conditions; temperature $T_{\infty}=289 \mathrm{~K}$, density $\rho_{\infty}=1.23 \mathrm{~kg} / \mathrm{m}^{3}$, pressure $p_{\infty}=1.013 \times 10^{5} \mathrm{~N} / \mathrm{m}^{2}$, and sound speed $c_{\infty}=340 \mathrm{~m} / \mathrm{sec}$. The ratio of specific heats is $\gamma=c_{p} / c_{v}=1.4$ and the reference length is $l_{\text {ref }}=0.305 \mathrm{~m}$.

\subsection{METHOD OF SOLUTION}

The unsteady Euler equations (Eq. (1)) are solved using an explicit finite difference scheme. The scheme, which is a generalization of MacCormack's scheme obtained by Gottlieb and Turkel ${ }^{2}$, is fourth-order accurate in space and second-order accurate in time. The numerical scheme, applied to a one-dimensional equation of the form

$$
\frac{\partial u}{\partial t}=\frac{\partial F}{\partial x}
$$

consists of a predictor step given by

$$
u_{i}^{*}=u_{i}^{n}+\frac{\Delta t}{6 \Delta x}\left[-7 F_{i}+8 F_{i+1}-F_{i+2}\right]
$$

followed by a corrector step of the form

$$
u_{i}^{n+1}=\frac{1}{2}\left[u_{i}^{*}+u_{i}^{n}+\frac{\Delta t}{6 \Delta x}\left[7 F_{i}^{*}-8 F_{i-1}^{*}+F_{i-2}^{*}\right]\right] .
$$

In the above equations, the subscript $i$ denotes the spatial grid point and the superscript $n$ the time level. Superscript $\left({ }^{*}\right)$ corresponds to an intermediate time level (between $n$ and $(n+1)$ ). The fourth-order accuracy is obtained by alternating the scheme given above with its symmetric variant. Operator splitting is used to reduce the two-dimensional problem to a sequence of onedimensional problems. If $L_{x}$ and $L_{y}$ denote the solution operators for the one-dimensional $x$ and $y$ problems. The solution to Eq. (1) is then obtained by

$$
Q^{n+2}=L_{x} L_{y} L_{y} L_{x} Q^{n}
$$


The beam equation, given by Eq. (5), is solved using a numerical technique derived by Hoff and Pahl ${ }^{14}$.

In addition to the high-order accuracy required by acoustic problems, the use of nonreflective boundary conditions is critical. Any boundary reflection would lead to spurious oscillations and nonphysical results. In order to minimize the effect of boundaries on the solutions presented in this TM, large computational domains are used whenever possible. In addition, all the boundary conditions are specified according to the four characteristics

$$
\begin{array}{cccc}
p+\rho c u, & p-\rho c u, \quad v \quad \text { and } \quad c_{\infty} \rho-p / c_{\infty} \text { in the x-direction } \\
p+\rho c v, & p-\rho c v, \quad u \quad \text { and } \quad c_{\infty} \rho-p / c_{\infty} \quad \text { in the y-direction. }
\end{array}
$$

Over the rigid walls, the normal velocity is zero; whereas, over the flexible surface the normal velocity of the fluid is set equal to the out-off-plane velocity of the surface. The four characteristics of Eq. (13) represent the acoustic waves (first and second), the vorticity wave (the third), and the entropy wave (the fourth). In addition to the boundary conditions given by Eq. (13), in the far-field, the Bayliss and Turkel ${ }^{8}$ radiation boundary condition given by

$$
p_{t}+c_{\infty} p_{r}+\left(p-p_{\infty}\right) /(2 r)=0
$$

is used. This boundary is known to be effective and accurate in simulating outgoing waves. The radius $r$ in this case represents the distance from the exit duct axis to the boundary point being considered. When simulating an acoustically absorbing surface, i.e., an impedance boundary, the normal velocity is no longer zero but is rather computed by the flow solver. For time-harmonic waves, the linear, normal momentum equation can be written as

$$
j \omega \rho_{\infty} v+p_{y}=0 .
$$

Using the definition of impedance given by $Z_{a c}=p / v$ leads to

$$
j \omega \rho_{\infty} p+Z_{a c} p_{y}=0 .
$$

Taking the acoustic impedance of an orifice to be approximately

$$
Z_{a c} \approx j \omega \rho_{\infty} \frac{2 \Delta y}{\Delta x \times 1}
$$

with the denominator representing a surface area $(S=\Delta x \times 1)$ of the orifice. For a square grid, $\Delta x=\Delta y$, the equation satisfied by the pressure at the impedance wall reduces to

$$
p+2 p_{y}=0
$$

The plane acoustics waves introduced at the inflow of the duct are of the form 


$$
p=\varepsilon \sum_{i} \cos \left(\omega_{i} t+\phi_{i}\right)
$$

with $\varepsilon$ being the amplitude of the waves and $\left(\omega_{i}, \phi_{i}\right)$ the frequency and phase. A discrete number of frequencies are used $(500,1000,1500,2000,2500,3000 \mathrm{~Hz})$ with corresponding phases of $(0, \pi / 3,2 \pi / 3, \pi, 4 \pi / 3,5 \pi / 3)$.

When the duct alone is used in the numerical experiments without the outside domain, a mean flow of the form

$$
U(y)=4 M_{p k} c_{\infty}\left(\frac{y}{H}\right)\left[1-\frac{y}{H}\right]
$$

is used, with $M_{p k}$ being the peak Mach number and $H$ the duct height.

\section{RESULTS AND DISCUSSIONS}

As previously mentioned, two computational domains were used - one composed of the duct alone and the other composed of the duct and its surrounding medium. The two computational domains are shown on Figure 1(a) and (b). In the duct alone case (Figure 1(a)), the computational domain is 2.75 feet by 0.167 foot in $x$ and $y$ directions with a respective number of points of 151 and 51 . This resolution leads to 15 points per wavelength at the high-frequency of $4000 \mathrm{~Hz}$, which is adequate for the high-accuracy scheme used. In the case of duct and its surrounding medium (Figure 1(b)), the computational domain used is 6 feet by 12 feet in $x$ and $y$ directions with a respective number of points of 301 and 601 . The duct height is taken to be 1 foot leading to 51 equally spaced points in the duct. The per-wavelength resolution is kept the same in both domains.

At first, code validations are performed. To this end, the results obtained by Longatte et al. ${ }^{15}$, for a duct with rigid walls, are used. In their numerical experiments on acoustic propagation in twodimensional sheared ducted flows the following inflow disturbance is used

$$
u(y, t)=\varepsilon U(y) \sin \left(\pi \frac{y}{H}\right) \sin \left(\frac{\Omega c_{\infty}}{H} t\right)
$$

where $U(y)$ is given by Eq. (20), $\varepsilon$ is the disturbance amplitude and $\Omega=\pi f / f_{1}^{c}$ with $f$ being the excitation frequency and $f_{m}^{c}=m c_{\infty} / 2 H$ the $m^{\text {th }}$ cutoff frequency of the duct. All the comparisons are made for $M_{p k}=0.08$ and $\varepsilon=0.05$. For $\Omega=2$, which is below the first cutoff frequency $f_{1}^{c}$, the plane acoustic mode is dominant as shown by Figure 2. Figure 2(a) shows the pressure contour plots in the duct and Figure 2(b) shows the time history of the fluctuating pressure at $x=\lambda$ along the centerline and at the top wall. The pressure contours are indeed those of plane waves and the two time histories are identical. 
For $\Omega=8$ both plane and oblique waves propagate down the duct as shown by the complex pressure contours of Figure 3(a). In addition, the time histories of the fluctuating pressure at $x=\lambda$ along the centerline and at the wall are now different as shown by Figure 3(b). For $\Omega=2 \pi$, the pressure distribution in the duct is shown on Figure 4(a). The figure shows an interaction between a longitudinal and a lateral mode. The time history, Figure 4(b), shows the centerline pressure to be higher than that at the wall. All these results are in excellent agreement with those of Longatte et al. ${ }^{15}$

\subsection{PLANE ACOUSTIC WAVE PROPAGATION IN A DUCT WITH AND WITHOUT MEAN FLOW}

\subsection{1 $M_{p k}=0$}

Numerical experiments are carried out to study the effects of the various surfaces on the propagation of plane acoustic waves, obtained using Eq. (19), in a duct. The length of the impedance wall is 38 centimeters $(\mathrm{cm})$ while that of the flexible surface is $28 \mathrm{~cm}$. The properties of the flexible surface are stiffness $D=40 \mathrm{Nm}$, mass per unit are $\rho_{p} h=2.714 \mathrm{~kg} / \mathrm{m}^{2} \mathrm{~m}$, Poisson's ratio $v=0.3$, physical damping $\Gamma=1.52 \times 10^{2} \mathrm{Ns} / \mathrm{m}^{3}$, and a length $L=0.304 \mathrm{~m}$. The first five natural frequencies are 134, 371, 727, 1198, and $1783 \mathrm{~Hz}$. Figure 5 shows the pressure contour plots for the various surface combinations; rigid top and bottom, rigid top and impedance bottom, flexible top and rigid bottom, and flexible top and impedance bottom. The figure shows that for the rigid surface case, the pressure contours are vertical, whereas in all the other cases the pressure contours exhibit a more complex shape. In particular, one can observe more pressure contours over the flexible surface and curved contours over the impedance wall.

Figure 6 shows the variation of the OSPL over the top wall of the duct as a function of the downstream distance for the various surfaces. It is clear from the figure that the case with impedance wall exhibits a drop in OSPL of nearly $30 \mathrm{~dB}$ near downstream exit of the duct. A negligible increase in OSPL is obtained over the flexible surface. When a flexible surface is used on the top wall and an impedance surface is used on the bottom wall, the OSPL near the exit of the duct is higher by about $5 \mathrm{~dB}$ over that given by the impedance wall alone. Therefore, the effect of the flexible surface is to increase the OSPL in the duct. Figure 7 shows the effect of the impedance wall on individual frequencies. The figure shows that at all the frequencies, the effect is nearly the same. This is expected, as the boundary condition used is frequency independent. Therefore, for this narrow duct, the impedance wall suppressed most of the acoustic disturbances downstream. However, when the duct width is increased from 0.167 foot to 1.0 foot the effect of the impedance wall on the OSPL measured on the top wall is negligible, Figure 8. This indicates that using an impedance wall to suppress plane waves propagating in a wide duct will not be as effective as in a narrow duct.

Figure 9 shows a comparison of power spectra near the center of the duct's top wall. The largest decrease in sound pressure level at all frequencies is achieved using the impedance wall alone. The decrease is more pronounced at $1000 \mathrm{~Hz}$ than it is at $3000 \mathrm{~Hz}$ at this location. When a flexible surface or a combination of a flexible surface and an impedance wall is used, additional 
frequencies are obtained that correspond to the structural frequencies and the SPL is slightly higher.

Figure 10 shows the time history of the pressure near the center of the top wall of the duct for the four different cases studied. In agreement with the previous results, the impedance wall case shows the most reduction in pressure fluctuations; whereas in the case of the flexible surface, an increase in fluctuations is obtained. Figure 11 shows the instantaneous spatial variation of the pressure along the duct center for the four different cases studied. Similar to the time history, the case of the impedance wall alone results in a large reduction of the amplitude of the pressure fluctuations. The flexible surface increases slightly the amplitude of oscillations.

\subsection{2 $M_{p k}=0.5$}

When a mean flow was introduced, the results changed as follows. The pressure distribution in the duct shown on Figure 12 shows less reduction in amplitude of the pressure over an impedance wall. Also the curved contours are now confined to the region near the wall. The flexible surface contribution is also reduced. The variation of the overall sound pressure level over the top wall of the duct with the downstream distance is shown on Figure 13. There is a significant reduction of the effect of the impedance wall on the OSPL. The decrease in OSPL over the length of the duct is reduced to about $20 \mathrm{~dB}$ from the $30 \mathrm{~dB}$ for the no-mean flow case. When a flexible surface is combined with an impedance wall, the reduction is even smaller (around $15 \mathrm{~dB}$ ). The power spectra at the center of the duct's top wall are shown on Figure 14. The effect of the mean flow is to reduce the damping effect of the impedance wall and the contribution of the flexible surface. The time history of the pressure at the center of the duct's top wall is shown on Figure 15. Similar to the no-flow case, the impedance wall leads to a reduction in the amplitude of the pressure fluctuations. The flexible surface, however, has very little effect. The spatial variation of the pressure at the duct center for the four different cases is shown on Figure 16. Similar to the time history, the amplitude of the pressure fluctuation is reduced with the use of an impedance surface.

\subsection{DIRECTIVITY OF ACOUSTIC WAVES PROPAGATING AWAY FROM A DUCT}

In this section only the no mean flow results are presented $\left(M_{p k}=0\right)$. The duct in this case is $28-\mathrm{cm}$ wide and $84-\mathrm{cm}$ long. Figure 17 shows a comparison of pressure contour plots for the rigid surface case and the case with an impedance wall at the bottom and for a plane wave frequency of $500 \mathrm{~Hz}$. There are small differences between the two plots both inside and outside the duct. Similarly, a comparison of pressure contour plots between a rigid and impedance-flexible surface on the top wall of the duct shows a very clear difference, Figure 18. Radiation from the flexible surface is dominating the acoustic field both inside and outside the duct. Figure 19 shows the directivity pattern along a semi-circle of radius 2 feet centered at the exit of the duct. The use of the impedance surface results in slightly lowering the far field OSPL. The strongest effect is obtained when a flexible surface is used on the top wall. In this case the directivity pattern is asymmetric and an increase of about $7 \mathrm{~dB}$ is obtained at various points in the upper quadrant. Combining a flexible surface with an impedance wall slightly reduces the OSPL. The time history of the pressure 2 feet downstream of the exit of the duct is shown on Figure 20. Slightly 
lower fluctuation amplitudes are obtained with the use of the impedance wall, whereas the flexible surface increases the level of the fluctuations and the frequency content. The spatial variation of the pressure along the centerline of the duct and outside is shown on Figure 21. The figure shows the propagation and decay of the acoustic waves. Enhanced decay is obtained with the impedance wall.

\section{CONCLUDING REMARKS}

Results are obtained for plane acoustic wave propagation in a duct over rigid, impedance, and flexible surfaces with and without mean flow. The results showed that using the impedance wall leads to a decrease in the overall sound pressure level downstream. However, the presence of a flexible surface results in an increase of the OSPL in the duct and outside. Downstream of the duct, the directivity pattern is also affected by the various duct surfaces. Using a flexible surface results in an asymmetric directivity with an increase in OSPL on the side of the flexible surface. The impedance wall also affects the directivity, but only slightly. This later result is found to be due to the increased duct width. Therefore the impedance wall is more effective at reducing the downstream OSPL in narrow ducts.

\section{REFERENCES}

1. Vu, B.T.; Kandula, M.; Margasahayam, R.N.; and Ford, D. M., "Launch Systems Testbed: An Innovative Approach for Design and Development of Future Launch Structures," Space Technology and Applications International Forum (STAIF 03), Albuquerque, NM, Feb. 26, 2003.

2. Gottlieb, D. and Turkel, E., "Dissipative Two-Four Methods For Time-Dependent Problems," Mathematics of Computation, Vol. 30, 1976, pp. 703-723.

3. Tam, C.K.W. and Auriault, L., "Time-Domain Impedance Conditions for Computational Aeroacoustics," AIAA Journal, Vol. 34, No. 5, 1996, pp. 917-923.

4. Jameson, A.; Schmit, W.; and Turkel, E., AIAA paper 81-1259.

5. Thompson, K.W., "Time-Dependent Boundary Conditions for Hyperbolic Systems, II," Journal of Computational Physics, Vol. 89, 1990, pp. 439-461.

6. Giles, M.B., "Nonreflecting Boundary Conditions for the Euler Equation Calculations," ALAA Journal, Vol. 28, No. 12, 1990, pp. 2050-2058.

7. Giles, M.B., "Nonreflecting Boundary Conditions for the Euler Equation Calculations," Computational Fluid Dynamics Lab., TR 88-1, Massachusetts Institute of Technology. Cambridge, MA, Feb. 1988. 
8. Bayliss, A. and Turkel, E., "Radiation Boundary Conditions for Wave-Like Equations," Communications on Pure and Applied Mathematics, Vol. 33, 1980, pp. 707-725.

9. Ozyoruk, Y. and Long, L.N., "Time-Domain Calculation of Sound Propagation in Lined Ducts with Sheared Flows," AIAA Journal, Vol. 38, No. 5, 2000, pp. 768-773.

10. Watson, W.R.; Jones, M.G.; Tanner, S.E.; and Parrot, T.L., "Validation of a Numerical Method for Extracting Liner Impedance," AIAA Journal, Vol. 34, No. 3, 1996, pp. 548-554.

11. Frendi, A.; Maestrello, L.; and Bayliss, A.; "On the Coupling Between a Supersonic Boundary Layer and a Flexible Surface," AIAA Journal, Vol. 31, 1993, pp. 708-713.

12. Frendi, A.; Maestrello, L.; and Bayliss, A., "Coupling Between Plate Vibration and Acoustic Radiation," Journal of Sound and Vibration, Vol. 177, No. 2, 1994, pp. 207-226.

13. Frendi, A., "Coupling Between a Supersonic Turbulent Boundary Layer and a Flexible Structure," AIAA Journal, Vol. 35, No. 1, 1997, pp. 58-66.

14. Hoff, C. and Pahl, P.J., "Development of an Implicit Method With Numerical Dissipation From a Generalized Single-Step Algorithm for Structural Dynamics," Computer Methods in Applied Mechanics and Engineering, Vol. 67, No. 2, 1988, pp. 367-385.

15. Longatte, E.; Lafon, P.; and Candel, S., "Computation of Acoustic Propagation in TwoDimensional Sheared Ducted Flows," AIAA Journal, Vol. 38, No. 3, 2000, pp. 389-394. 
(a)

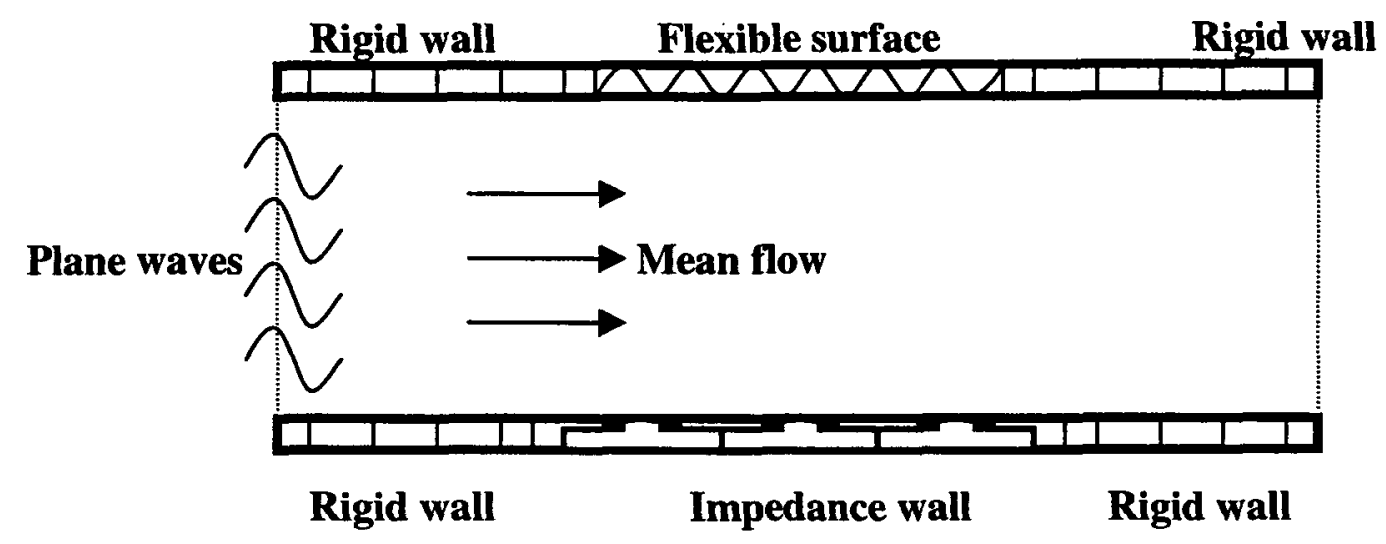

(b)

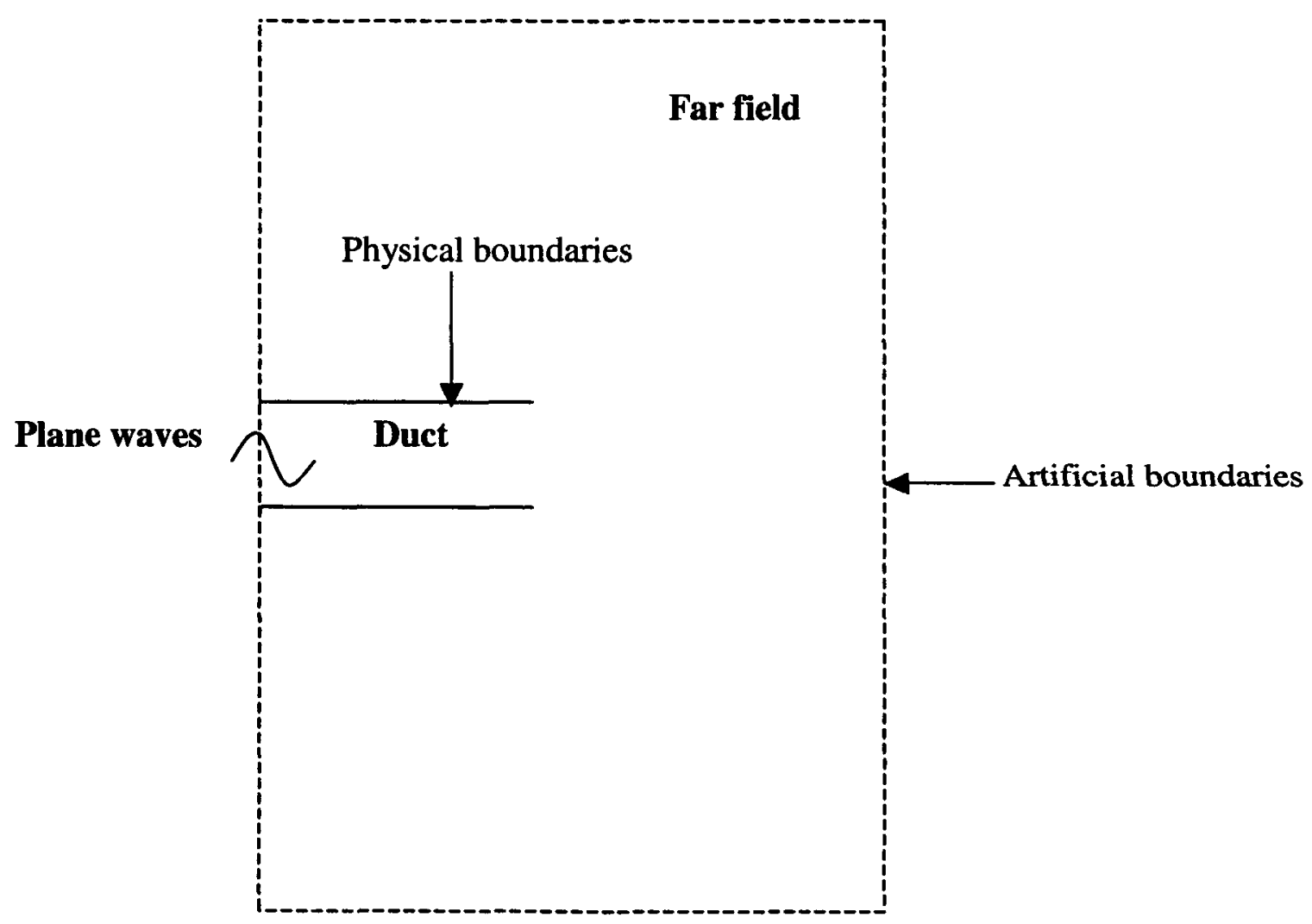

Figure 1. Computational domains: (a) duct alone, (b) duct and surroundings 
(a)

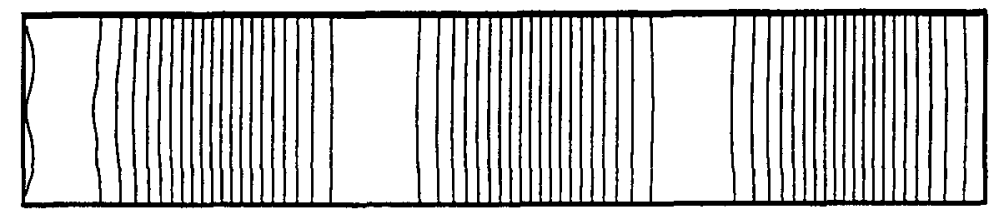

(b)

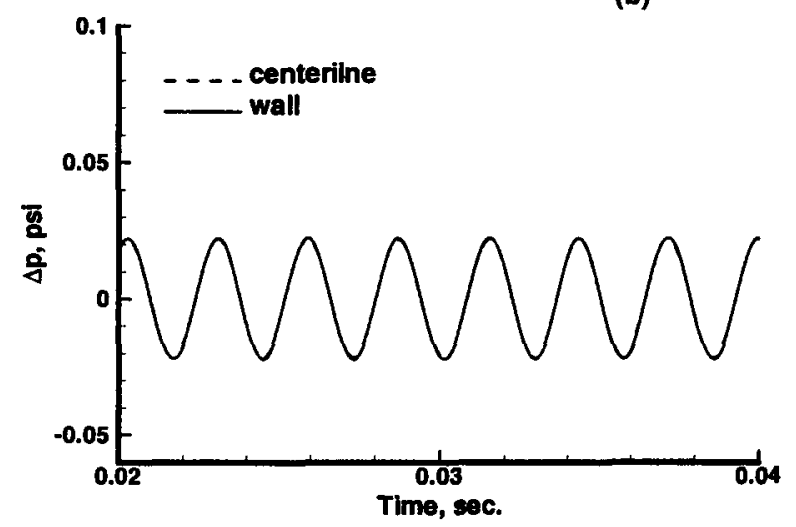

Figure 2. (a) Pressure distribution in the duct for $\Omega=2$, (b) Time history of the pressure fluctuations at $x=\lambda$

(a)

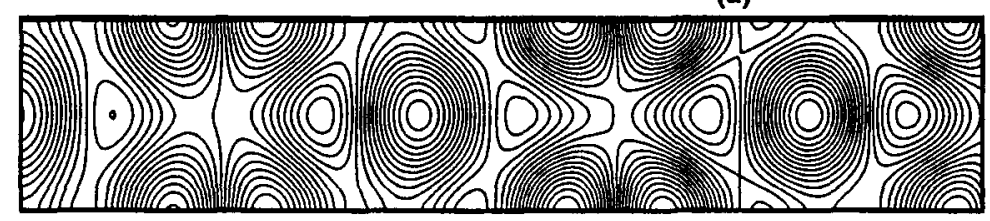

(b)

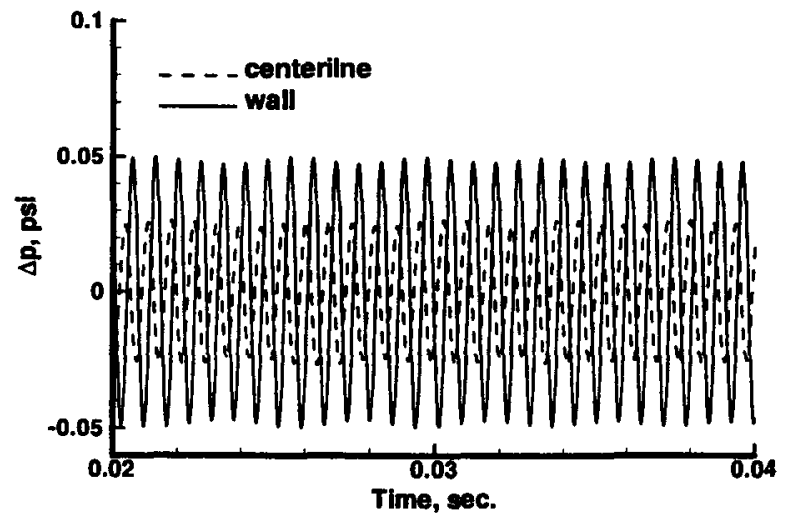

Figure 3. (a) Pressure distribution in the duct for $\Omega=8$, (b) Time history of the pressure fluctuations at $x=\lambda$ 
(a)

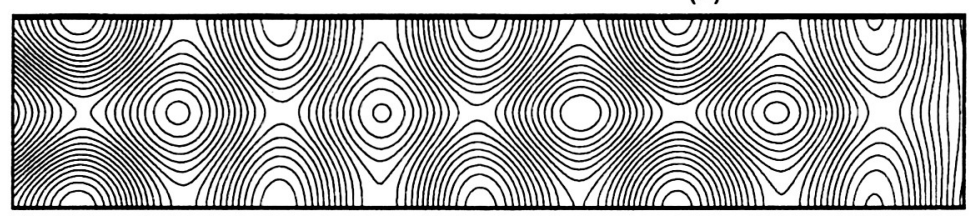

(b)

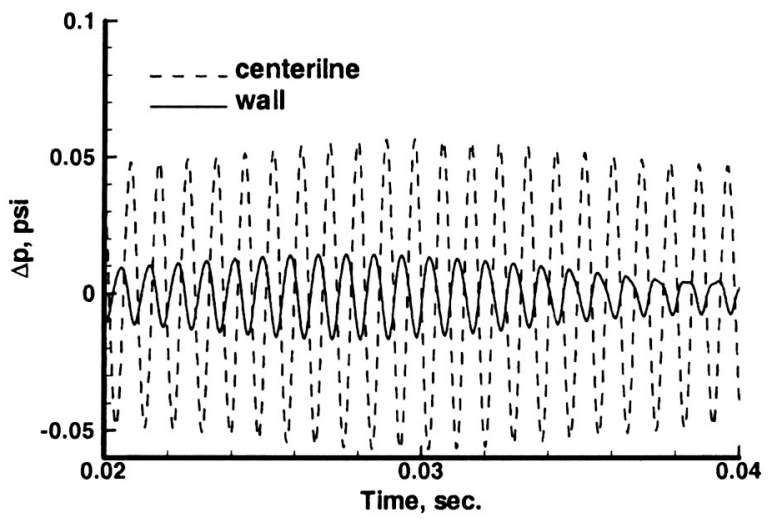

Figure 4. (a) Pressure distribution in the duct for $\Omega=2 \pi$, (b) Time history of the pressure fluctuations at $x=\lambda$
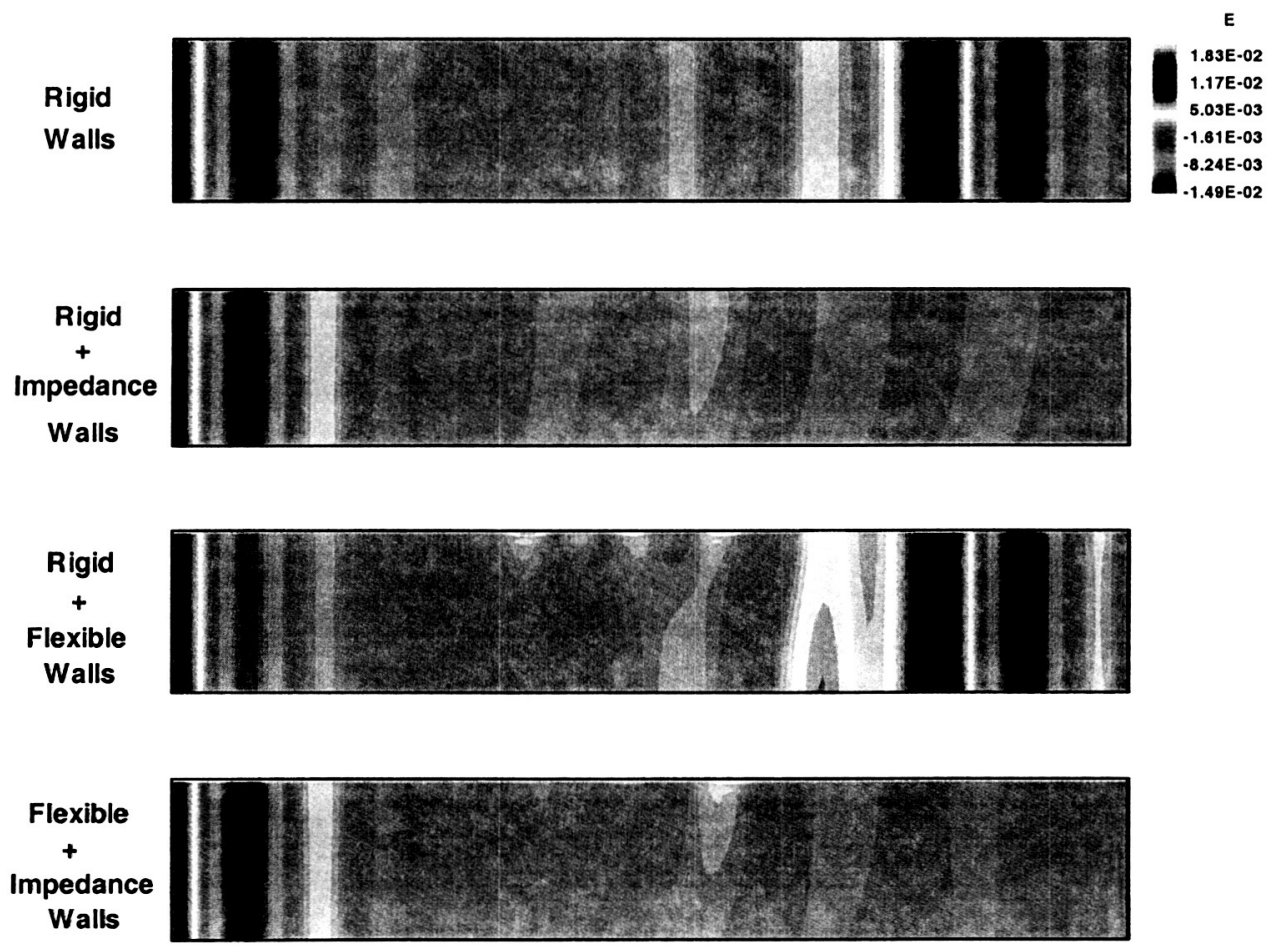

Figure 5. Instantaneous pressure contours in the duct for $\mathrm{M}_{\mathrm{pk}}=0$ 


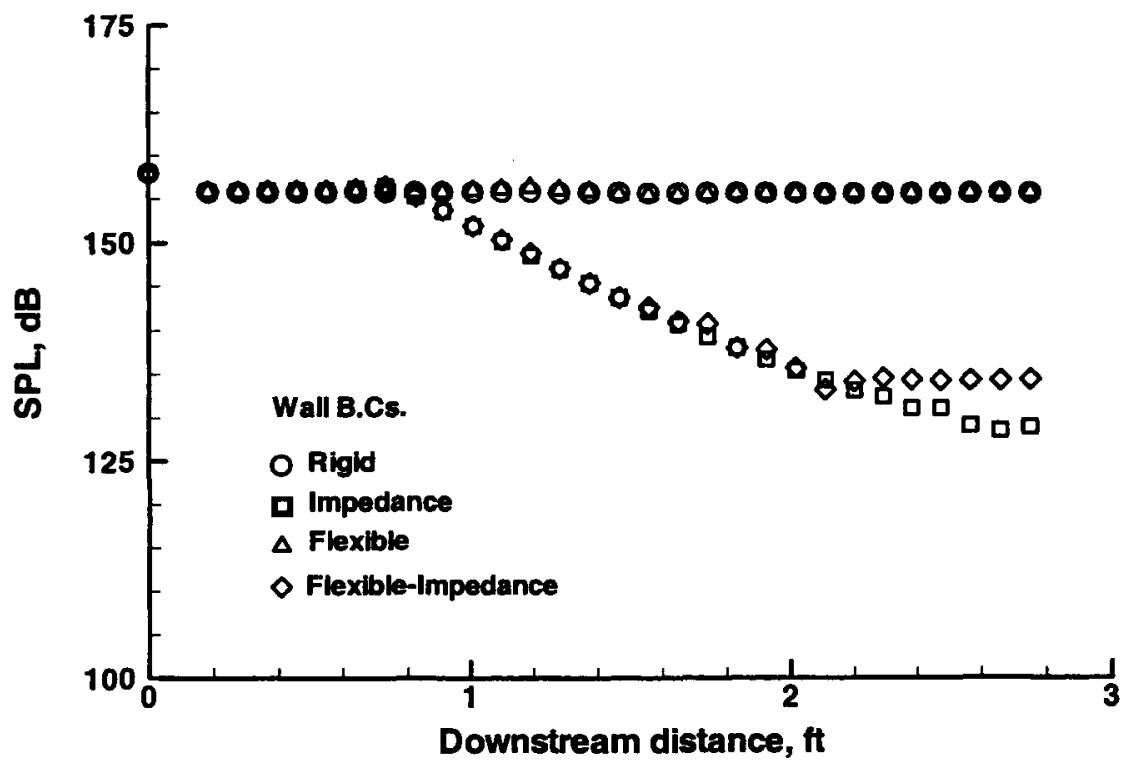

Figure 6. Overall Sound Pressure Level (OSPL) along the top wall of the duct

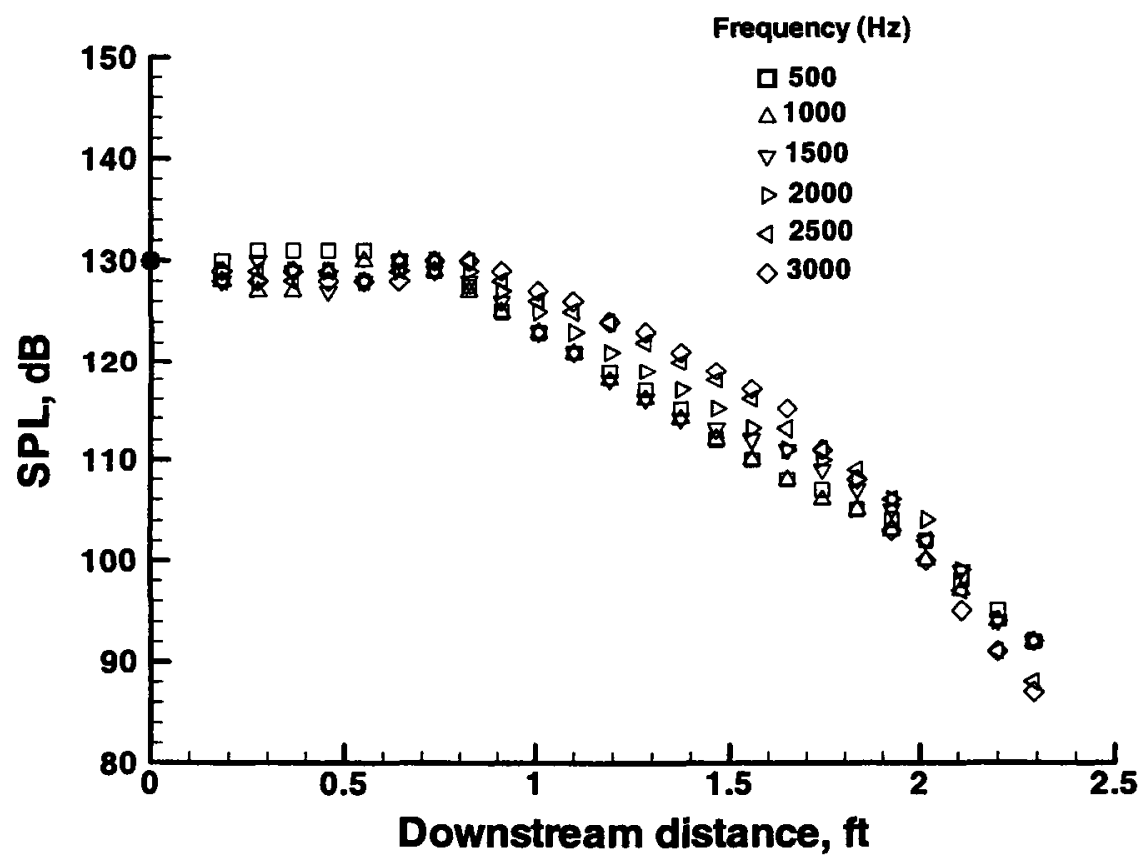

Figure 7. Sound Pressure Level along the top wall for the various frequencies and for the case of the impedance bottom with $\mathrm{M}_{\mathrm{pk}}=0$ 


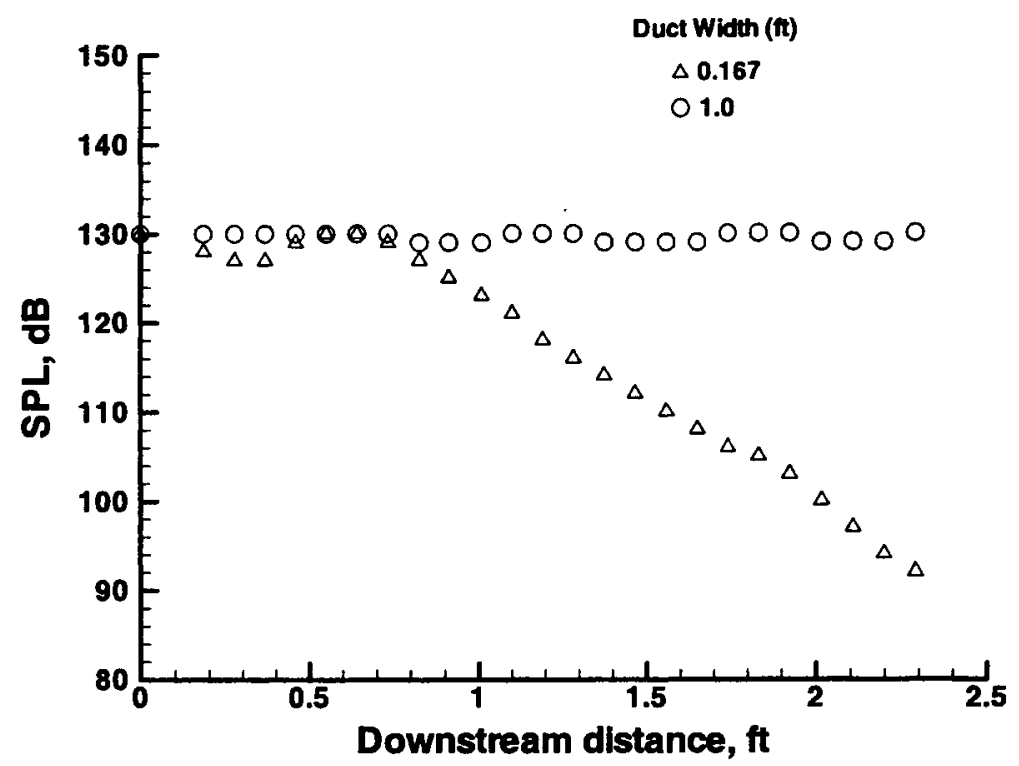

Figure 8. Sound Pressure Level along the top wall for $f=1000 \mathrm{~Hz}$ and for the case of the impedance bottom with $M_{p k}=0$
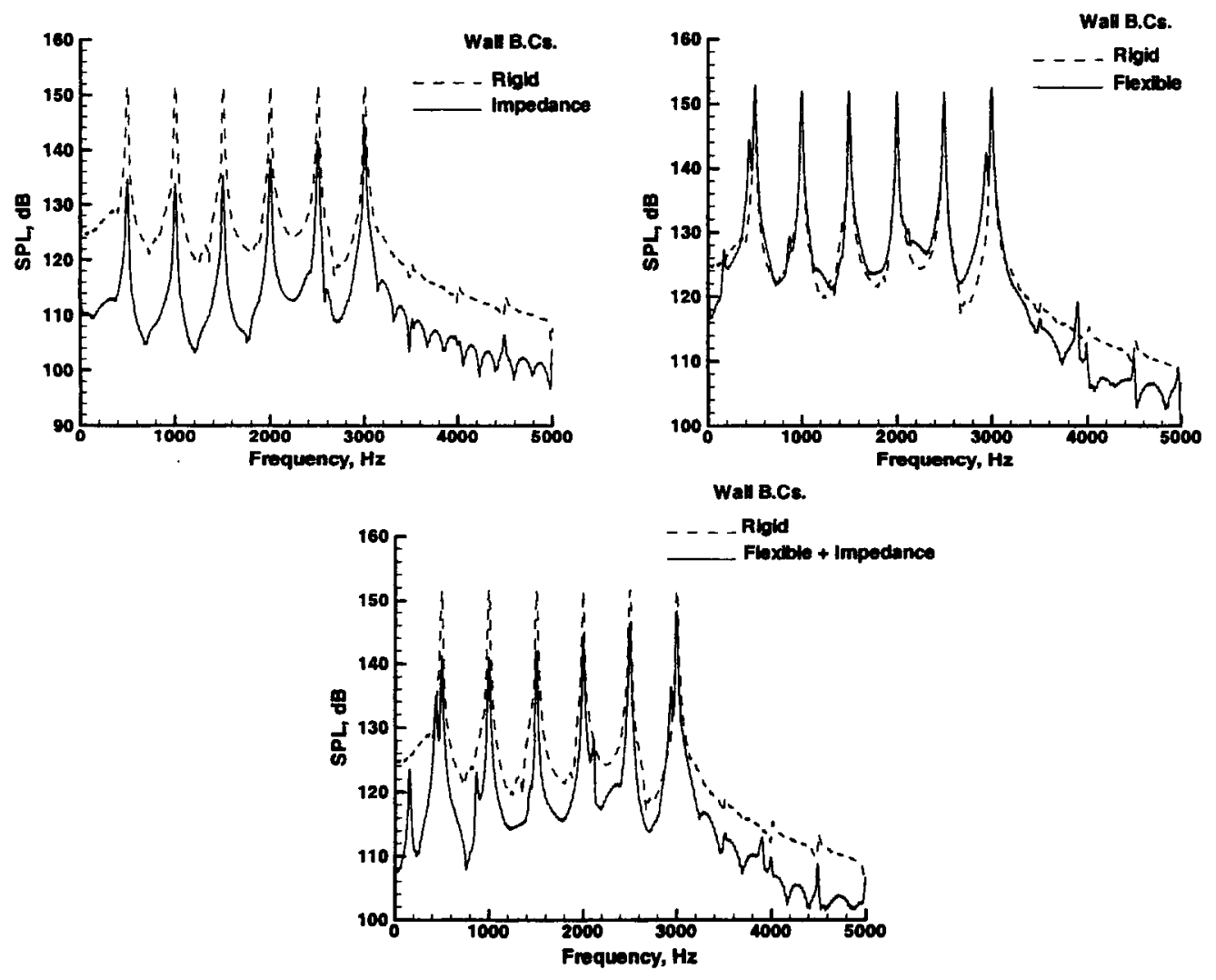

Figure 9. Comparison of pressure power spectra at the center of the top wall of the duct obtained with the various surfaces 

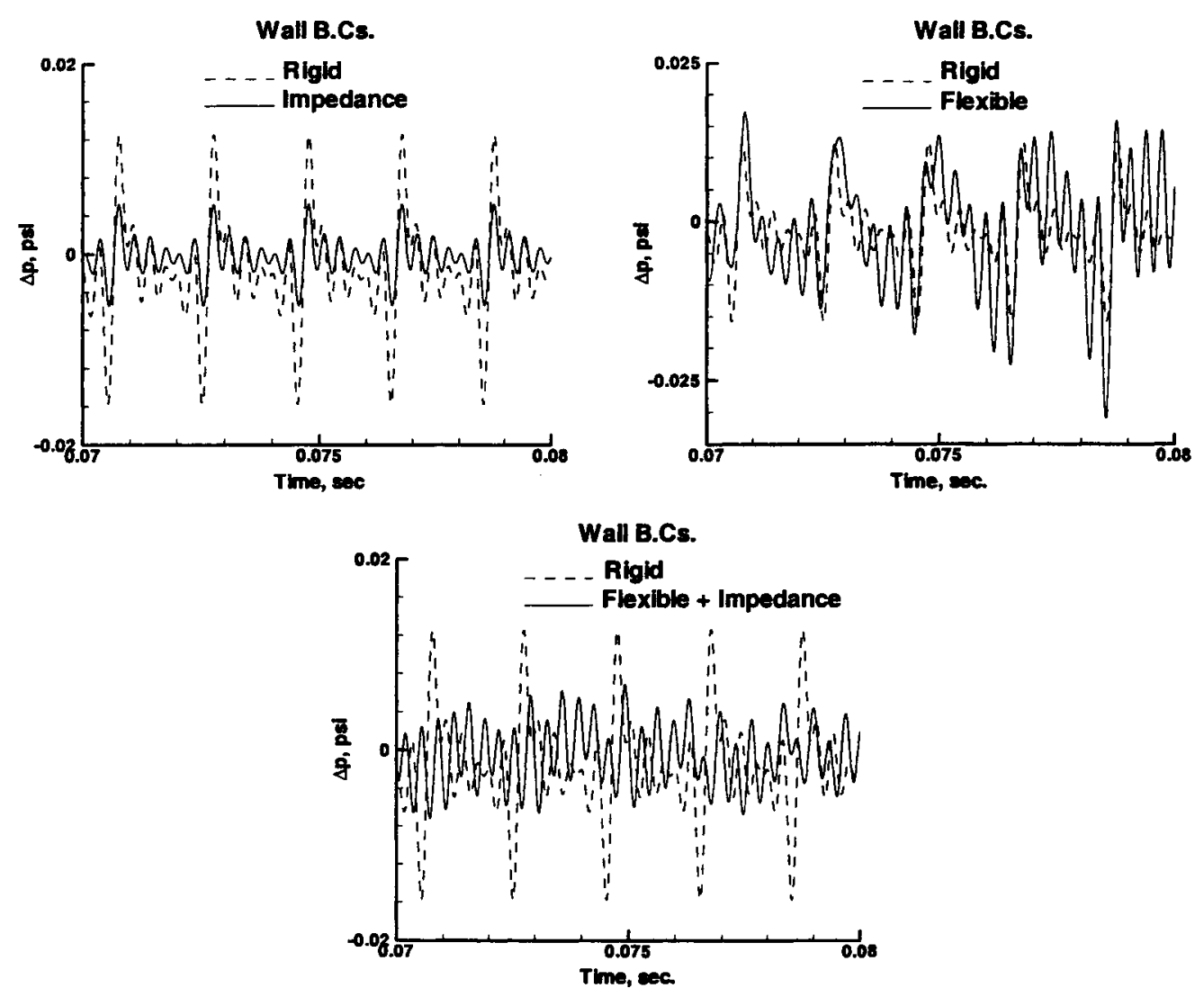

Figure 10. Comparison of the time history of the fluctuating pressure at the center of the top wall of the duct obtained for the various surfaces

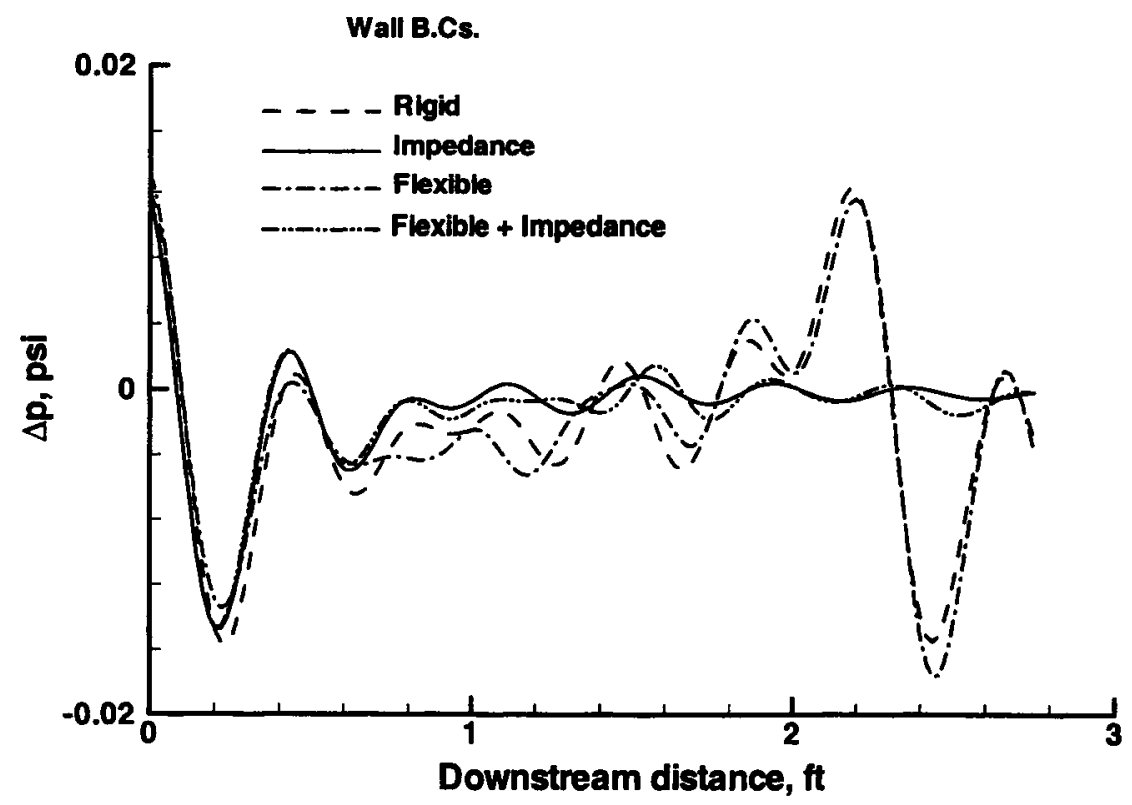

Figure 11. Comparison of the instantaneous spatial variation of the fluctuating pressure obtained for the various surfaces 

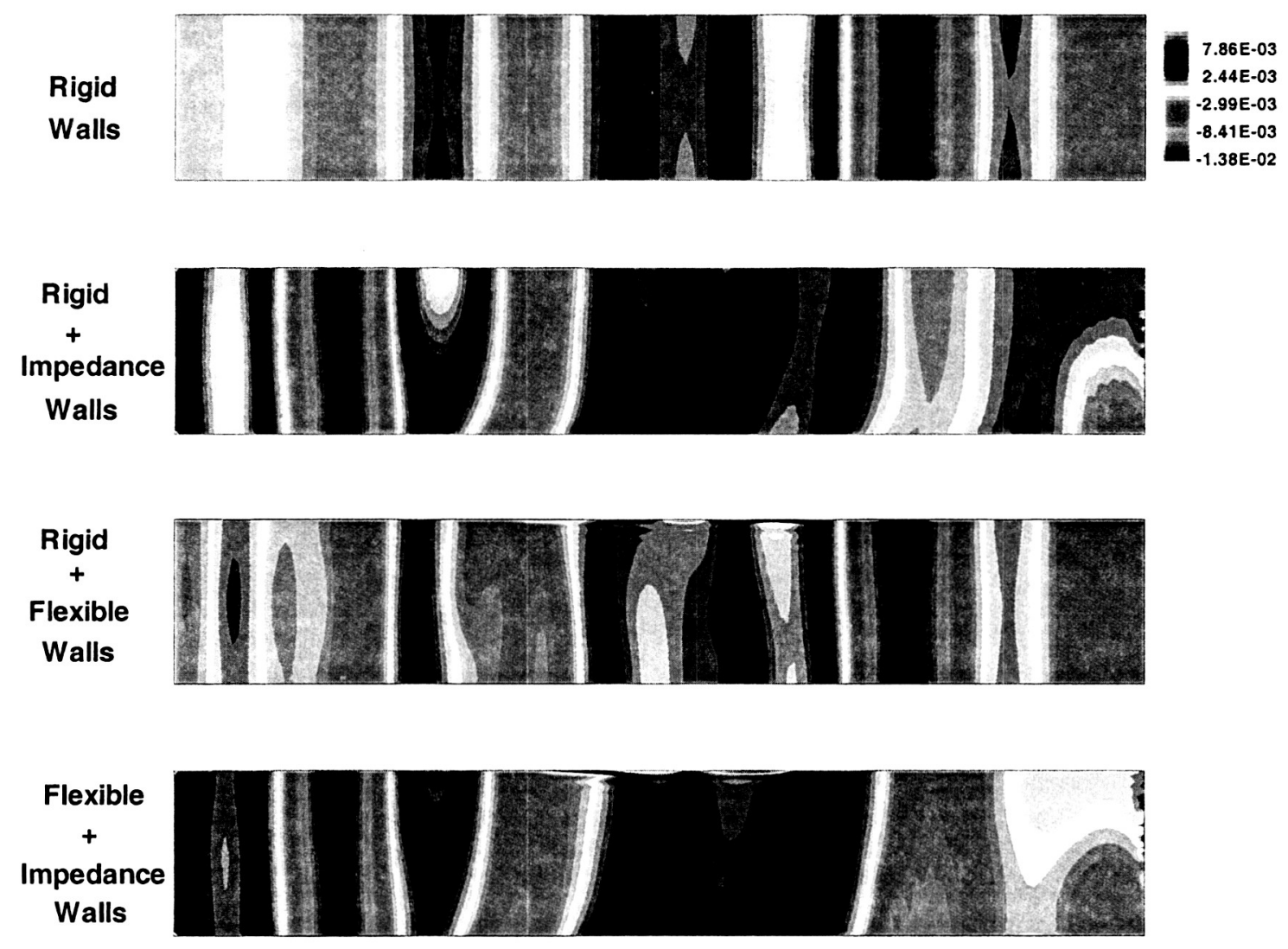

Figure 12. Instantaneous pressure contours in the duct for $M_{p k}=0.5$

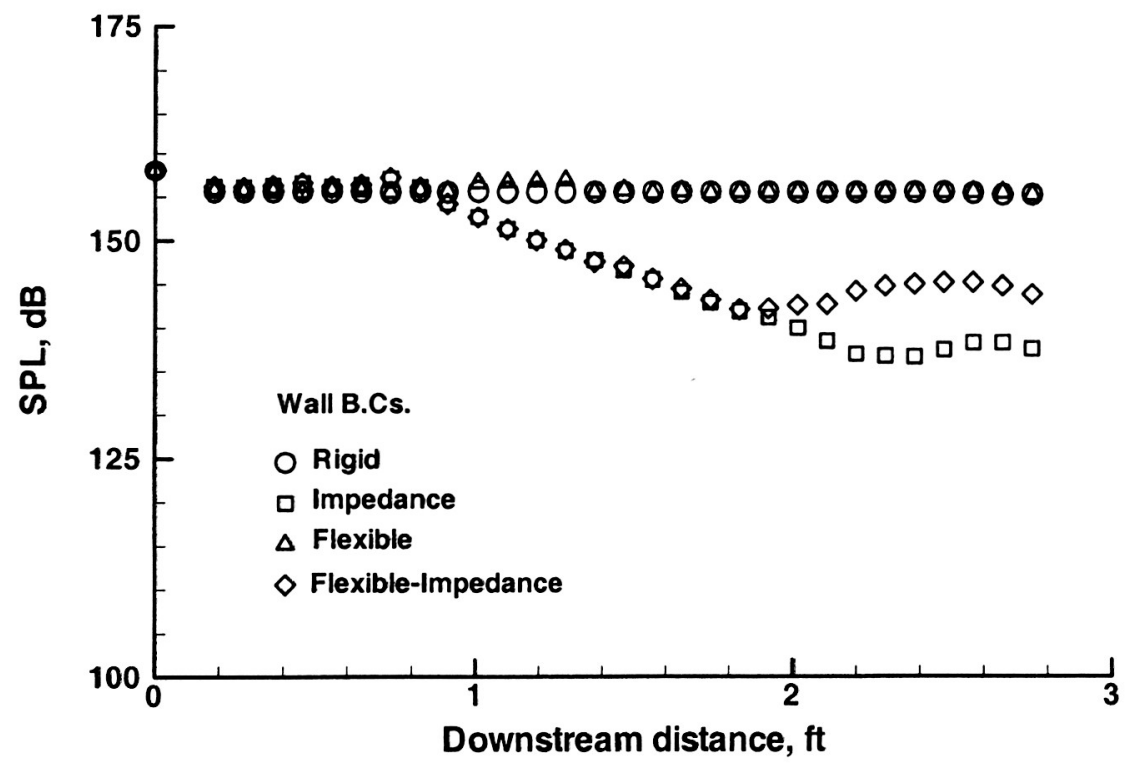

Figure 13. Overall Sound Pressure Level along the top wall of the duct 

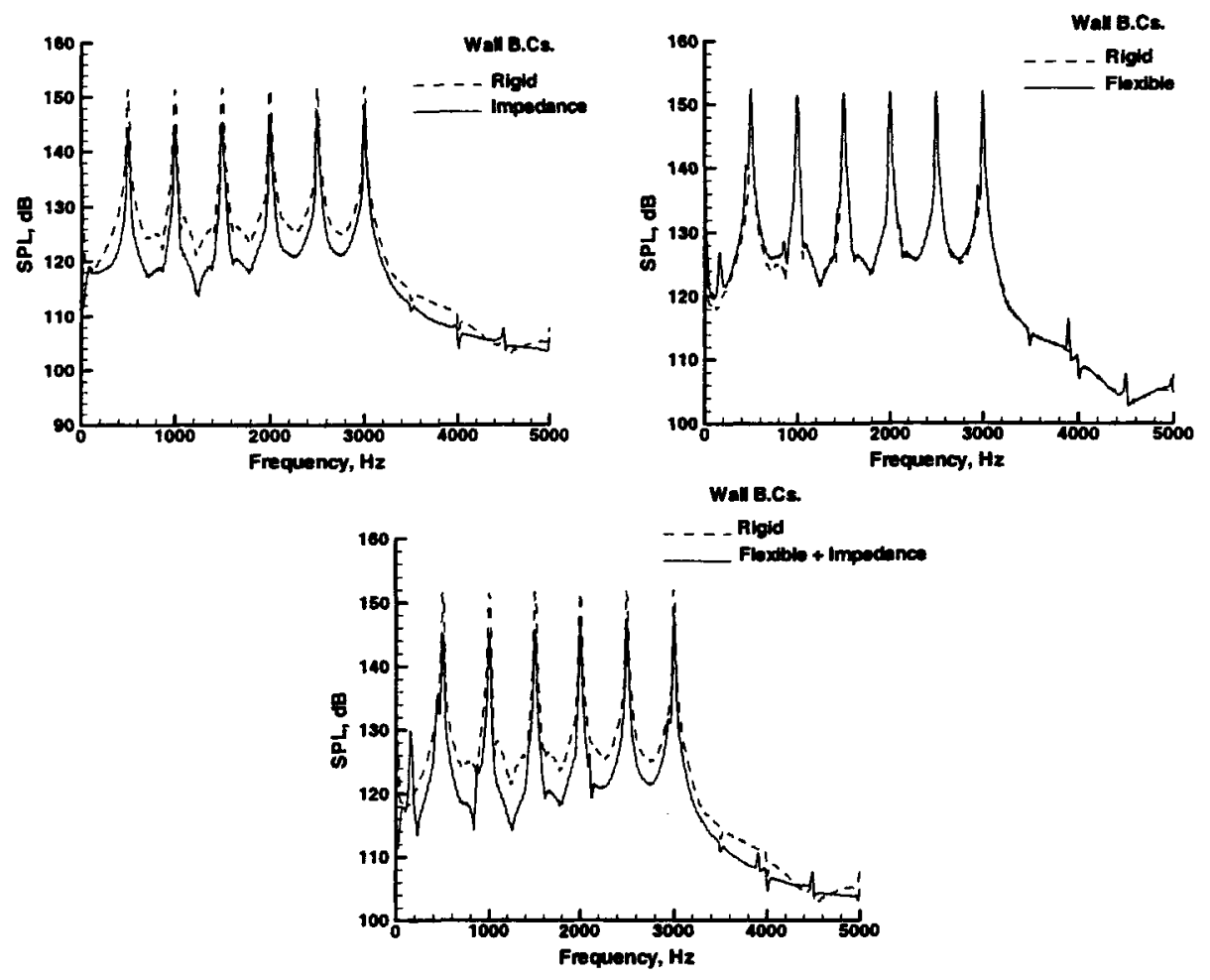

Figure 14. Comparison of pressure power spectra at the center of the top wall of the duct obtained with the various surfaces
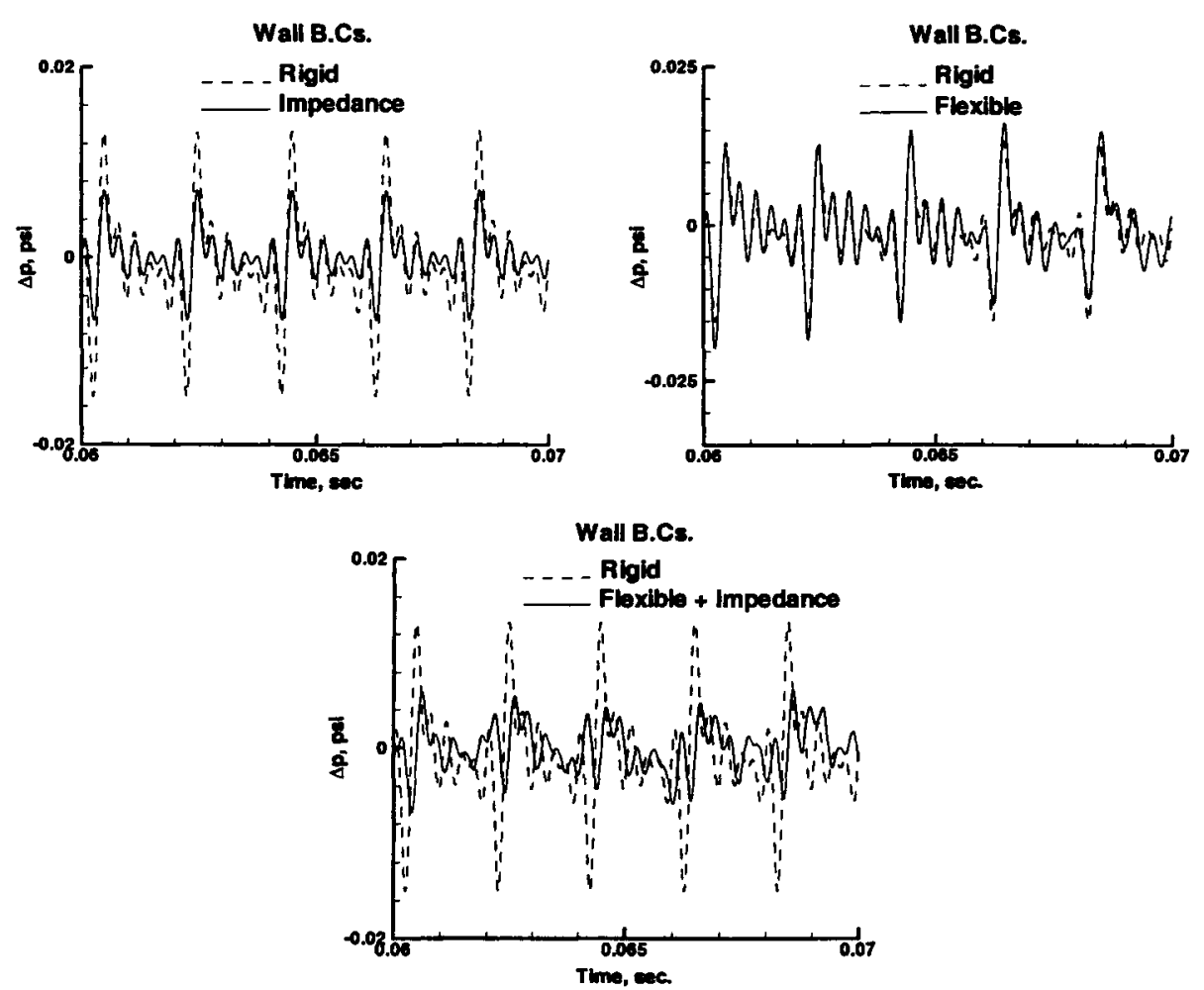

Figure 15. Comparison of the time history of the fluctuating pressure at the center of the top wall of the duct obtained for the various surfaces 


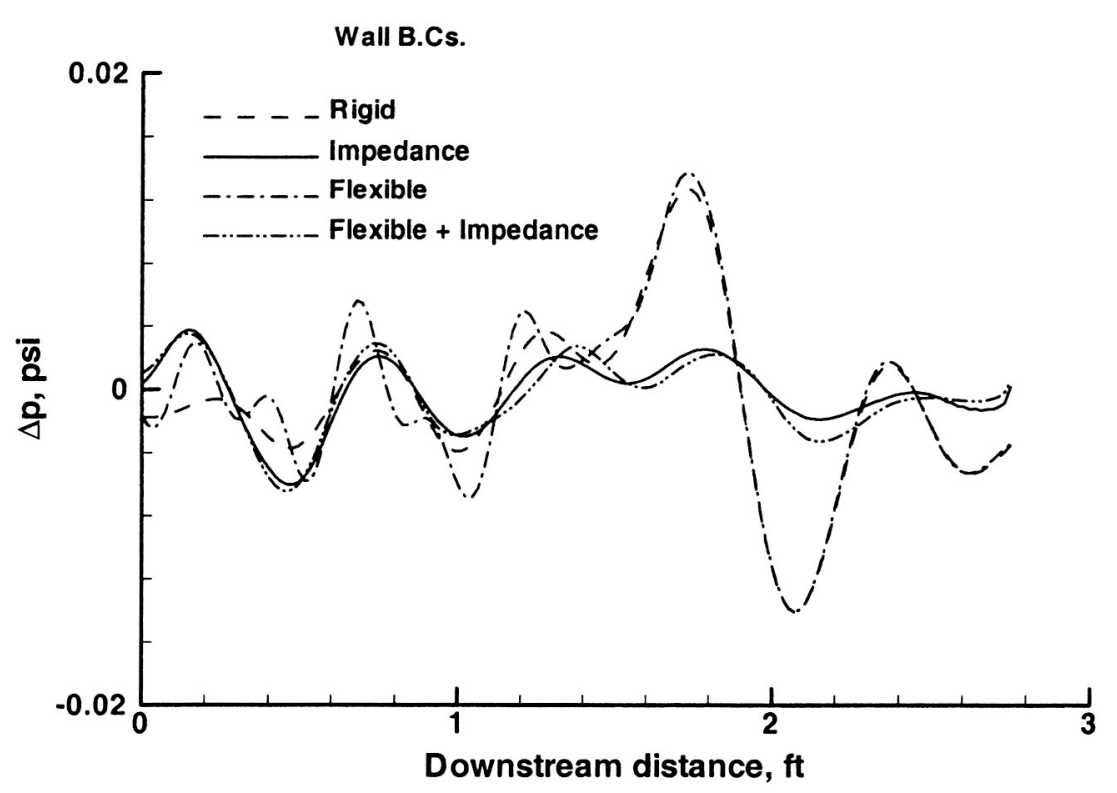

Figure 16. Comparison of the instantaneous spatial variation of the fluctuating pressure obtained for the various surfaces

Rigid Wall Boundary Conditions

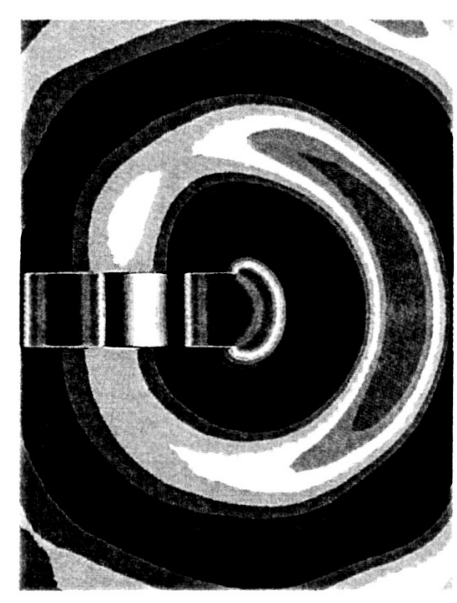

Impedance Wall Boundary Conditions

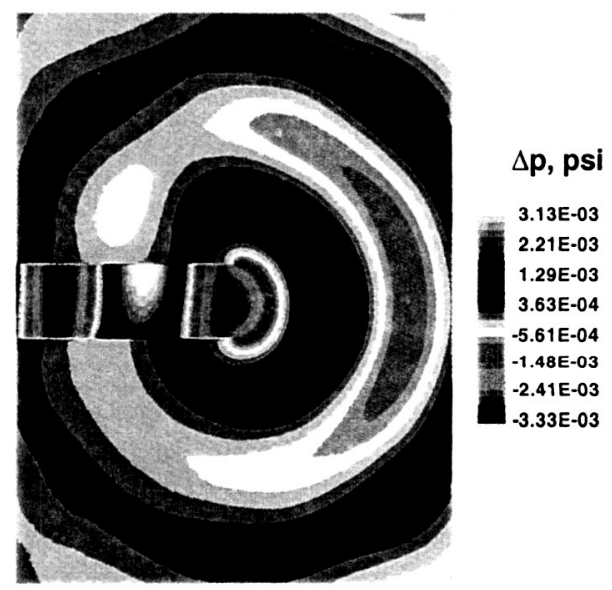

Figure 17. Instantaneous pressure contours in the duct and its surroundings for the rigid and impedance surface cases $\left(M_{p k}=0, f=500 \mathrm{~Hz}\right)$ 
Rigid Wall Boundary Conditions

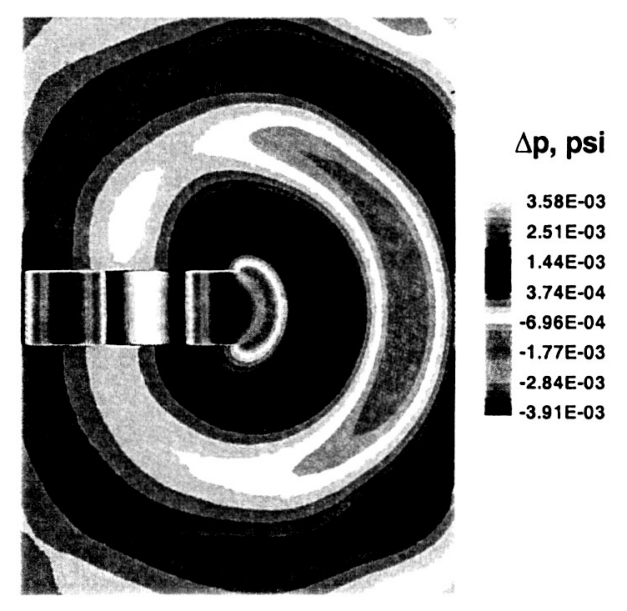

Flexible Wall Boundary Conditions

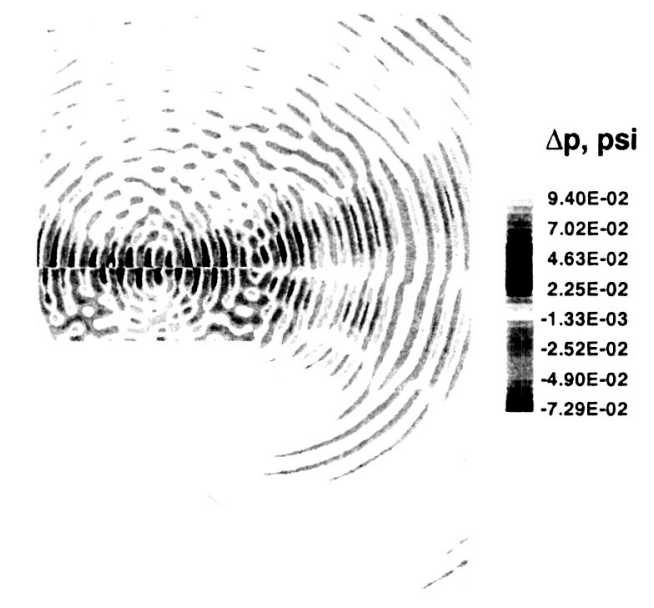

Figure 18. Instantaneous pressure contours in the duct and its surroundings for the rigid and the impedance-flexible surface cases $\left(M_{p k}=0, f=500 \mathrm{~Hz}\right)$

$$
\begin{aligned}
& \text { Wall B.C.s } \\
& 0 \text { Rigid } \\
& \diamond \text { Imp. (Bot.) } \\
& \square \text { Flexible (top) } \\
& \Delta \text { Flex. + Imp. }
\end{aligned}
$$

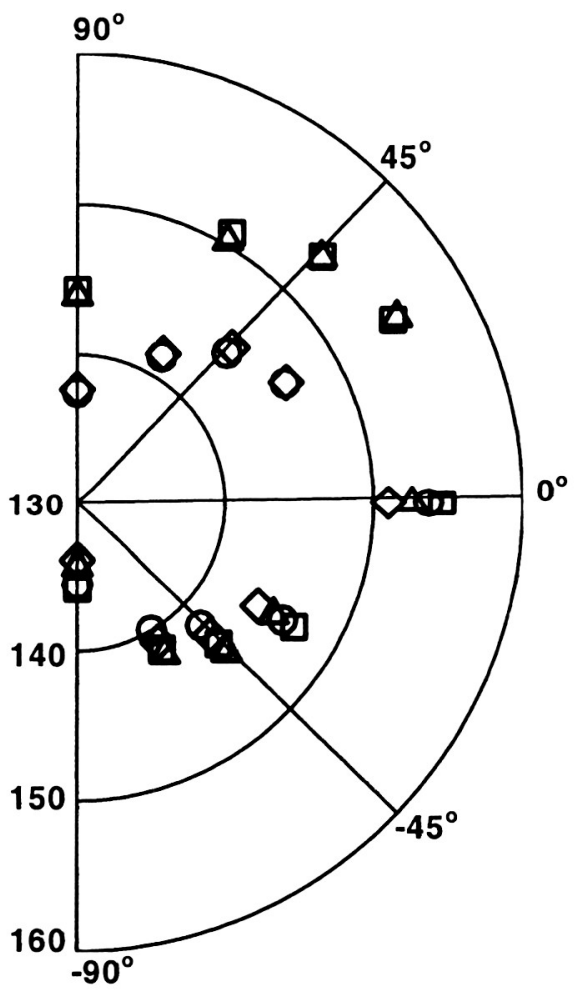

Figure 19. Far field SPL directivity obtained with the various surfaces at a distance of 2 feet from the exit of the duct $\left(M_{p k}=0\right)$ 

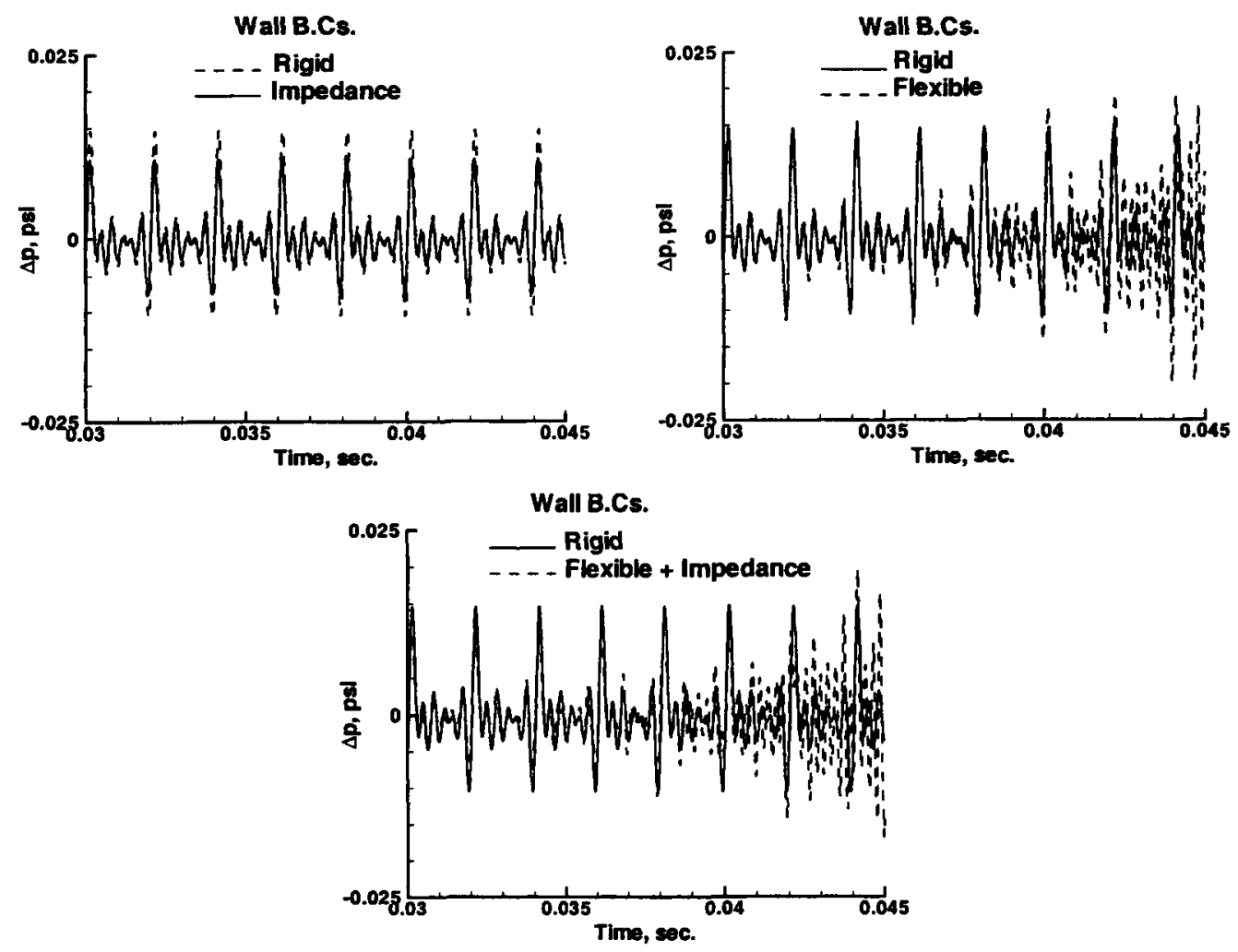

Figure 20. Comparison of the time history of the fluctuating pressure 2 feet downstream from the exit of the duct $\left(M_{p k}=0\right)$

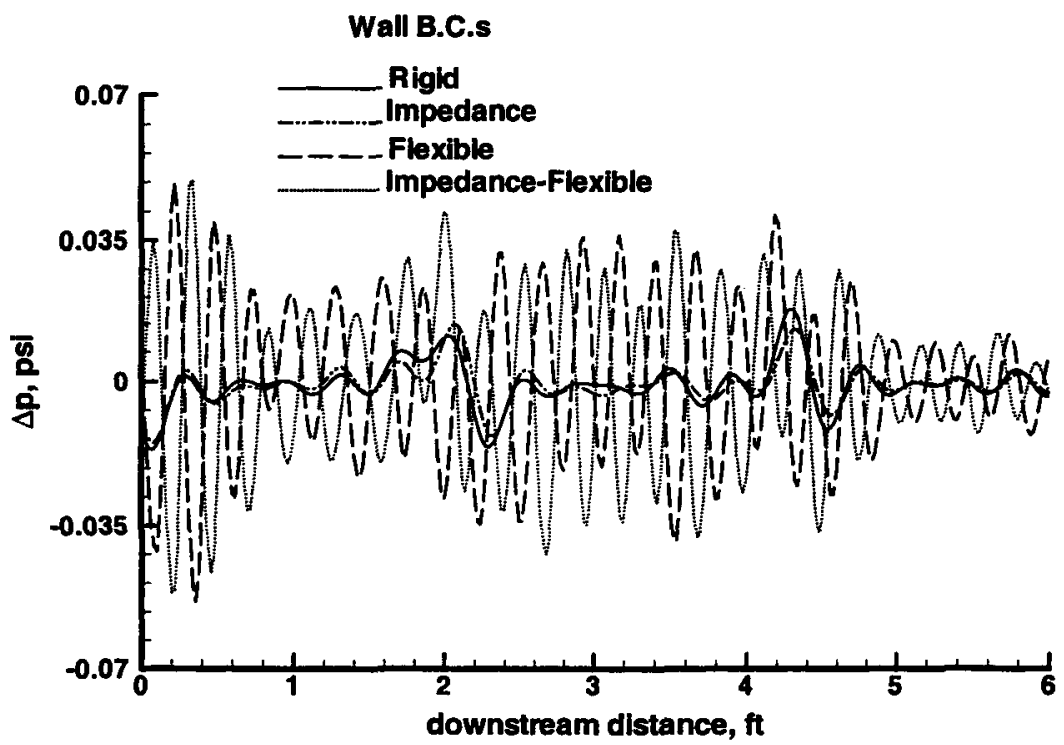

Figure 21. Comparison of the instantaneous pressure variation with the downstream distance along the center of the duct and outside $\left(M_{p k}=0\right)$ 


\begin{tabular}{|c|c|c|c|}
\hline \multicolumn{3}{|c|}{ REPORT DOCUMENTATION PAGE } & $\begin{array}{l}\text { Form Approved } \\
\text { OMB No. 0704-0188 }\end{array}$ \\
\hline \multicolumn{4}{|c|}{ 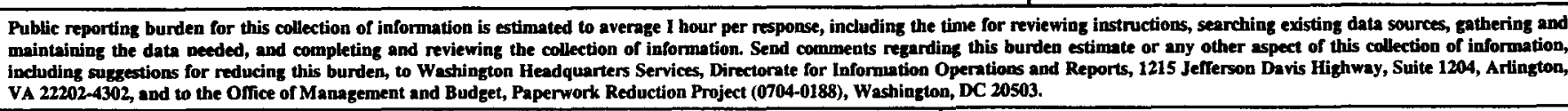 } \\
\hline 1. AGENCY USE ONLY (Leave blank) & $\begin{array}{l}\text { 2. REPORT DATE } \\
\text { March } 2003\end{array}$ & & $\begin{array}{l}\text { EE AND DATES COVERED } \\
\text { al Memorandum-2003 }\end{array}$ \\
\hline \multicolumn{3}{|c|}{$\begin{array}{l}\text { 4. TTILE AND SUBTITLE } \\
\text { On the Propagation of Plane Acoustic Waves in a Duct With } \\
\text { Flexible and Impedance Walls }\end{array}$} & \multirow{2}{*}{ 5. FUNDING NUMBERS } \\
\hline \multicolumn{3}{|c|}{$\begin{array}{l}\text { 6. AUTHOR(S) } \\
\text { Bruce Vu } \\
\text { Abdelkader Frendi, University of Alabama in Huntsville }\end{array}$} & \\
\hline \multicolumn{3}{|c|}{$\begin{array}{l}\text { 7. PERFORMING ORGANIZATION NAME(S) AND ADDRESS(ES) } \\
\text { NASA YA-C2-T, Kennedy Space Center, FL } 32815 \\
\text { University of Alabama in Huntsville } \\
\text { Huntsville, AL }\end{array}$} & $\begin{array}{l}\text { 8. PERFORMING ORGANIZATION RE- } \\
\text { PORT NUMBER }\end{array}$ \\
\hline \multicolumn{2}{|c|}{$\begin{array}{l}\text { 9. SPONSORING/MONITORING AGENCY NAME(S) AND ADDRESS(ES) } \\
\text { Spaceport Engineering and Technology } \\
\text { Mail Code: YA-C2-T } \\
\text { Kennedy Space Center, FL } 32815\end{array}$} & & $\begin{array}{l}\text { 10. SPONSORING/MONTTORING } \\
\text { AGENCY REPORT NUMBER } \\
\text { NASA/TM-2003-211185 }\end{array}$ \\
\hline
\end{tabular}

11. SUPPLEMENTARY NOTES

\begin{tabular}{|l|l|}
\hline $\begin{array}{l}\text { 12a. DISTRIBUTION/AVALABILITY STATEMENT } \\
\text { Unclassified - Unlimited } \\
\text { Distribution: Standard } \quad \text { Availability: NASA CASI }\end{array}$ & 12b. DISTRIBUTION CODE: \\
\hline
\end{tabular}

13. ABSTRACT (Maximum 200 words)

This Technical Memorandum (TM) discusses the harmonic and random plane acoustic waves propagating from inside a duct to its surroundings. Various duct surfaces are considered, such as rigid, flexible, and impedance. In addition, the effects of a mean flow are studied when the duct alone is considered. Results show a significant reduction in overall sound pressure levels downstream of the impedance wall for both mean flow and no mean flow cases and for a narrow duct. When a wider duct is used, the overall sound pressure level (OSPL) reduction downstream of the impedance wall is much smaller. In the far field, the directivity is such that the overall sound pressure level is reduced by about 5 decibels $(\mathrm{dB})$ on the side of the impedance wall. When a flexible surface is used, the far field directivity becomes asymmetric with an increase in the OSPL on the side of the flexible surface of about 7 dB.

\begin{tabular}{|c|c|c|c|}
\hline \multirow{2}{*}{\multicolumn{3}{|c|}{$\begin{array}{l}\text { 14. SUBJECT TERMS } \\
\text { sound propagation, plane acoustic waves, ducts, overall sound pressure } \\
\text { levels }\end{array}$}} & $\begin{array}{l}\text { 15. NUMBER OF PAGES } \\
27\end{array}$ \\
\hline & & & 16. PRICE CODE \\
\hline $\begin{array}{l}\text { 17. SECURTYY CLASSIFICATION } \\
\text { OF REPORT } \\
\text { unclassified }\end{array}$ & $\begin{array}{l}\text { 18. SECURITY CLASSIFICATION } \\
\text { OF THIS PAGE } \\
\text { unclassified }\end{array}$ & $\begin{array}{l}\text { 19. SECURITY CLASSIFICATION } \\
\text { OF ABSTRACT } \\
\text { unclassified }\end{array}$ & $\begin{array}{l}\text { 20. LIMITATION } \\
\text { OF ABSTRACT }\end{array}$ \\
\hline
\end{tabular}


National Aeronautics and

Space Administration

John F. Kennedy Space Center

Mail Code YA-C2-T

Kennedy Space Center, Florida 32899
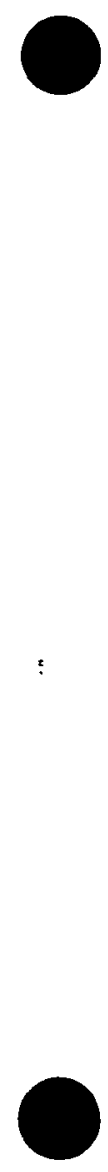